\title{
Effects of Problem Based Learning on Students' Achievement and Attitude Towards Physics (Mechanics): The Case of Gilgel Beles College of Teachers Education
}

\author{
Semeneh Bedemo \\ Department of Physics Education, Gilgel Beles College of Teacher's Education, Benishangul Gumuz, Ethiopia
}

Email address:

Semenehb31@gmail.com

\section{To cite this article:}

Semeneh Bedemo. Effects of Problem Based Learning on Students' Achievement and Attitude Towards Physics (Mechanics): The Case of Gilgel Beles College of Teachers Education. Science Journal of Education. Vol. 8, No. 3, 2020, pp. 71-81. doi: 10.11648/j.sjedu.20200803.12

Received: June 8, 2020; Accepted: June 22, 2020; Published: July 28, 2020

\begin{abstract}
Problem based learning as a preferred teaching method was tested and proved as stated in the result section of this research. The objective of this study was to determine the effects of problem-based learning (PBL) on students' academic achievement and attitude towards Mechanics (Physics). The study was conducted at Gilgel Beles College of Teachers Education (GBCTE) on first year physics students. From 150 physics students 60 students were taken using systematic random sampling. In the study, data were obtained through, the use of pre-test post-test, experimental $(\mathrm{N}=30)$ - control $(\mathrm{N}=30)$ group model. Two types of instruments were used for measurement: achievement tests, and survey method using five Likert scale questionnaires to know students' attitude towards mechanics and PBL. Pilot study was carried out on 15 students of the same background but not in the sample group to test the reliability of the questionnaire items and achievement test items. The calculated Cronbach alpha coefficient was 0.80 and 0.79 , respectively. The data obtained from both groups were analyzed using SPSS window 16.0 . Descriptive statistics mean and standard deviation were used to describe students' achievement test scores and their questionnaire responses. Meanwhile, independent samples t-test was used to see significance difference between experimental and control group in academic achievement and attitude towards mechanics. The experimental group was taught mechanics using PBL while conventional teaching method was applied for control group. Frequency distribution was used to know students' attitude towards PBL. Results in tables 5 and 8 indicated that implementing problem-based learning approach improved $8.76 \%$ of students' academic achievement and 3.56\% of attitude towards Mechanics. Students developed positive attitude towards problem-based learning, their academic achievement and attitude towards mechanics were positively correlated. At college level teachers are encouraged to implement problem-based learning method in teaching science concepts, especially physics.
\end{abstract}

Keywords: Education, PBL, Achievement and Attitude

\section{Introduction}

The help of physics manifested in our day to day life through science and technical areas, the structure of matter, and unknown aspects of the universe. Physics is very important in most fields of science and technology due to its outstanding scientific discoveries. Merely telling is not teaching and simply listening is not learning [1]. Again some learning process revolves around the teacher, where the students are only passive information receivers. While in students centered learning process teacher is merely facilitator or guide is the focal point of modern systems of education. In all active learning process, the learners learn according to their own needs and pace [2]. They are given the opportunities to make decisions regarding various dimensions of the learning process and to perform self-regulation. In case of active learning process, learning is not a standard process but a personalized process. Human beings face a multiple dimensional problem in their lives and they try to solve these problems in a particular way in the light of their previously gained knowledge and experiences. In this regard it is essential for the students to be prepared for future or near future challenges by facing real life, or real like, problems in their learning environment, and finding appropriate solution of these problems. Each society expects from its education system that it enables the individuals to become an effective problem 
solver in their real life [3, 4]. The roots of problem-solving learning are found in Dewy's thoughts, "that learning by experimentation or doing is more lasting" [5]. The problem solving is how to learn independently. It is the most convenient approach to achieve the aims of teaching learning process. According to [6] and [7], in present era problem-based learning is extensively used nearly in all areas including physics and was first implemented in medical education in 1950s. When we examine the related literature it is seen that research studies focused on the use of problem based learning in elementary, secondary and higher education have been reached [8-10], stated that we live in a dynamic society in which social, political and technological conditions are changing continuously, so educators should analyze and evaluate the trends in order to decide an appropriate curricula and method of instruction which will make students ready for real life situation. Today, it is recognized that every person must be empowered to suggest possible explanations, to propose ways to test personal or class, to collect and interpret data obtained, to communicate the process and results to others. In this era of unprecedented breakthroughs in technology and constant change in many aspects of life, educators are challenged more than ever before with the need to develop students who will be adaptable in fast-changing environments. This calls for equipping students with better thinking skills and learning abilities.

Researchers over the years are faced with finding relevant solutions to the problem of under achievement recorded in physics instruction yearly [11]. The achievement of students has become worrisome to the generality of the people especially physics educators and researchers [12, 2], confirmed that the use of appropriate instructional strategies can influence the performances of students.

Exploratory research has revealed the reason associated with students' attitudes towards physics courses and methods of teaching [13]. Researchers have highlighted that they take pleasure in physics course if the students know how to plan and implement the strategies of solution to the questions through teaching methods. Researcher has stated that, "the attitudes toward physics change with exposure to physics, but the level of change may be related to the quality of that exposure, the learning environment, and teaching method" [14]. The effect of solving problem on a student's attitude toward science is incredibly important because problem solving requires patience, persistence, perseverance, and willingness to accept risks [14]. Using effective methodology, science educators and their students can bridge the gap from thinking about science to thinking like scientists, moving to a more authentic view of science and science research.

We live in a world where society and technology are changing steadily. That is why every individual should own the skills of analyzing, discussing, explaining, researching, synthesizing, and communicating to be able to keep up with these changes. Today the needed people are the one who could make decisions and give logical solutions to real life problems. The instruction process is traditionally based on tests, books, and documents. The contents are explained; learners pay attention to what is taught and do the exercises at the end of the chapter. This procedure is not relevant as learners do not have a clear picture of experimentation; thus, they get confused.

Teachers, parents, and administrators are concerned that college graduates are not capable of making real life decisions. [15], stated that most of the questions that teachers ask in conventional teaching are direct questions and do not stimulate higher-order thinking. Educational reform must take place in colleges, new strategies are needed especially the ones that teach students to solve problems effectively. Conventional teaching strategies are teacher centered, where student passively receives information. While in students centered approaches the instructor is a mentor of the learning process and students have the options to make their own judgments about the different problems presented to them. People face different kind of problems in their lives and they use previously gained knowledge and experiences to find solutions to these problems. Thus, students should learn the way to deal with these challenges by confronting such problems during their learning process $[16,17]$.

Even though, traditional teaching methodologies exist in most educational settings, alternative techniques are also available to educators. Techniques that incorporate higher levels of thinking and problem solving should be considered. Problem Based Learning (PBL) is a strategy that helps students to acquire problem solving skills in addition to the skills of communicating, analyzing, researching, and accepting others. In this methodology, students are independent learners and teachers are facilitators who guide the learning process.

Today the needed people are the one who could make decisions and give logical solutions to real life problems. Conventional teaching process is traditionally based on tests, books, and documents. Teachers, parents, and administrators are concerned that college graduates are not capable of making real life decisions. Therefore, PBL is needed to produce real problem solvers. Few studies have been conducted regarding the effects of PBL on students' academic achievement and attitude towards physics at elementary and high school level. As to the knowledge of the researcher no studies have been conducted in Ethiopia regarding the Effects of PBL on students' academic achievement and attitude towards physics at college Level. Especially, at GBCTE PBL is almost none. This suggests further need to focus on effects of PBL on students' academic achievement and attitude towards mechanics. Therefore, the researcher has stated the following leading questions to see the effects of PBL on students' academic achievement, students' attitude towards mechanics and students' attitude towards PBL.

Does problem-based learning influence students' academic achievement in mechanics?

Does problem-based learning influence students' attitude towards mechanics?

What is the attitude of students towards PBL?

The general objective of the study is to investigate the 
effects of using problem-based learning instructional strategy on students' academic performance and attitudinal change in learning mechanics. Thus, the specific objectives of this study are to:

Compare the academic achievement of students using PBL and $\mathrm{CM}$ in learning mechanics.

Investigate students' attitude towards the first course in physics (mechanics) in the teachers training college when they are exposed to PBL.

Know attitude of students towards PBL.

\section{Materials and Methods}

\subsection{Research Design}

The design of research was experimental involving two equivalent groups: experimental and control group. The experimental group was treated with the program and exposed to PBL using selected topics from mechanics whereas the control group was taught the same topics by using traditional method. Both groups were treated in similar way except the program, assuming other conditions were constant. To investigate the effectiveness of problem based learning a problem-solving instructional technique were preferred in teaching mechanics for conceptual understanding.

A pre-test, post-test (mechanics achievement test), and attitude questionnaire were used for both experimental and control group. A self-developed standardized test was used as an instrument. The researcher developed pre-test to form equivalent groups and post-test to measure statistically significant difference.

The test consists 20 items containing 17 multiple choice questions and 3 practical solutions to problems to measure students' cognitive, affective, and psychomotor skills. All the items in the test were based on Newton's Laws of motion, conservation of momentum, collisions, and conservation of energy. The reliability of test items was checked by using Cronbach's Alpha (.79) and the validity by department committee in collaboration with two pedagogical science teachers that has long years of teaching experience. However, two questions were removed after reliability test.

\subsection{Subject of the Study}

This study was conducted in 2010/2011 academic year at GBCTE on $1^{\text {st }}$ year physics students, who took mechanics course in the Department of Physics. From the total number of 150 physics students, 60 volunteered students participated in the study and they were divided in to two groups based on their pre-test score: an experimental group (30) students and a control group (30) Students.

\subsection{Treatment}

Throughout this research all activities were carried out; out of the regular schedule (4 sessions per week, 50min per session). Before the experimental processes, pre-test was given during the first week for both groups. Problem based learning strategies training program was given to the experimental group at the beginning of the experiment, while those in the control group were taught only by course book/traditional problem-solving strategies. Namely: 1. Reading the problem, 2. Determining the given and asked variables, 3. Visualizing, 4. writing down the formulas related to the problem, and 5. Mathematical Solution.

Problem solving strategy in problem-based learning includes: Understanding the problem, qualitative analyzing of the problem, solution plan for the problem, applying the solution plan, and checking.

\subsubsection{Conventional Learning Tasks}

The traditionally designed mechanics instruction was based upon lessons employing lecture/questioning method to teach concepts of selected topics. Teaching strategies depend upon teacher's explanations, discussions, and textbooks. The teacher treated the entire class as a unit, wrote notes on the blackboard about the definition of different terminology and drew diagrams related to topics. After the teacher's explanation, the concepts were discussed, and recapitulated. The direction of communication in the classroom was from teacher to students. Here the teacher is the focal point of discussion and dispenser of the knowledge.

\subsubsection{Problem Based Learning Task}

In experimental group, before the treatment, five groups were formed containing six students in a group to facilitate PBL activities and the group variation did not considered in this study: these had different learning styles and academic performance based on their pre-test result. Then, students were trained to use problem-based learning for one week during the treatment. Every member of the group had some responsibilities. Students were supposed to participate actively in the group discussion. They had to share their knowledge, express their ideas and experience with each other while doing a solution to the problem. Apart from the group work, each student had to conduct an independent study and must be able to represent, communicate, and evaluate his/her learning either individually or at group level.

During the Problem based learning sessions, teacher organized the groups and created a purposeful and cooperative atmosphere. When guidance was needed, the teacher asked open-ended, very general questions and gave ample opportunity to students to focus on the goal. The teacher encouraged critical thinking. At the end of each activity, students evaluated each other with respect to participation, preparation, interpersonal skills, and contribution to group progress. In this way it was expected that students would become aware of the role, expected from them both individually and as a group. The experiment lasted for four weeks. After which the same post-test was administered for both groups.

\subsection{Samples and Sampling Technique}

From the total number of 150 physics students, researcher identified students who were volunteered to participate. Among these students who volunteered, an 
alphabetical list was created, and systematical random sampling was taken in the multiple of two until it reaches to 60 , this was $40 \%$ of the sample. It was then divided in to two groups as experimental (30) and control (30) based on the pre-test result using systematic sampling techniques taking one student from up and one student from low scorers until it reaches to 30 .

\subsection{Reliability Calculation}

\subsubsection{Pilot Study of Mechanics Achievement test}

Pilot-test (Appendix C-2) was carried out on 15 students with the same background with the treatment groups, but not in the sample group to determine the reliability of test items.

Table 1. Pilot test to determine reliability of achievement test items.

\begin{tabular}{llll}
\hline Questions & Item Mean & Cronbach's Alpha & N \\
\hline Q 1 & .67 & .78 & 15 \\
Q 2 & .73 & .77 & 15 \\
Q 3 & .73 & .77 & 15 \\
Q 4 & .80 & .77 & 15 \\
Q 5 & .53 & .77 & 15 \\
Q 6 & .47 & .80 & 15 \\
Q 7 & .60 & .79 & 15 \\
Q 8 & .73 & .76 & 15 \\
Q 9 & .53 & .82 & 15 \\
Q 10 & .40 & .78 & 15 \\
Q 11 & .67 & .78 & 15 \\
Q 12 & .67 & .77 & 15 \\
Q 13 & .67 & .77 & 15 \\
Q 14 & .47 & .78 & 15 \\
Q 15 & .47 & .77 & 15 \\
Q 16 & 1.87 & .81 & 15 \\
Q 17 & 1.3 & .81 & 15 \\
Q 18 & .87 & .79 & 15 \\
\hline
\end{tabular}

\begin{tabular}{ll}
\hline Average Cronbach's Alpha & Number of items \\
\hline .79 & 18 \\
\hline
\end{tabular}

Items 16,17 , and 18 were work out parts having maximum 5,2 , and 3 points, respectively. Items $1-15$ were multiple choice items scored 1 for a correct answer and 0 for an incorrect answer.
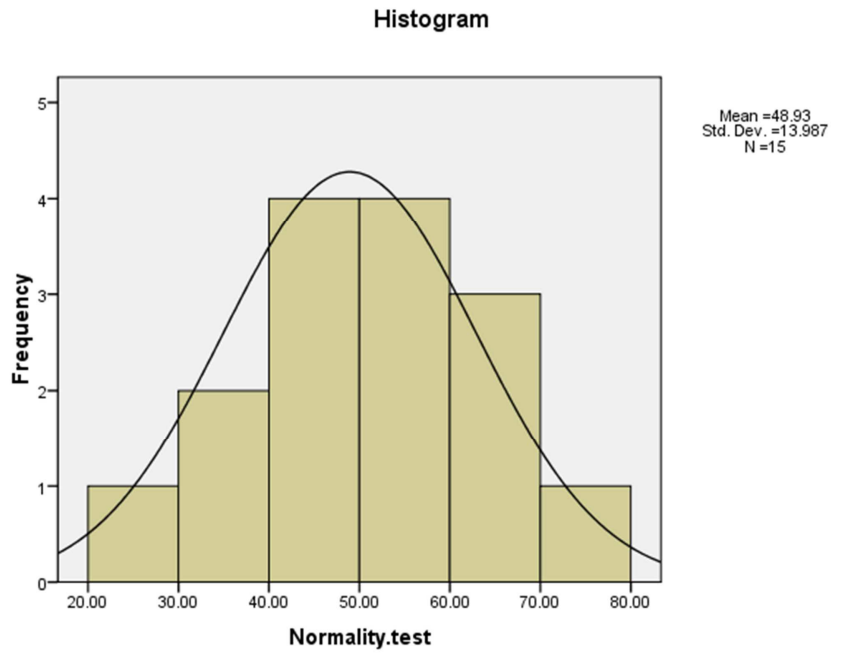

Figure 1. Normality test for achievement test scores.
As it is indicated in table 1, from 20 questions the reliability of 2 questions was below. 70 and hence, they were removed from the questions and 18 questions were delivered for post-test to both experimental and control groups. The internal consistency of the test was found to be high with a Cronbach's alpha value of .79. This value indicates a good reliability for the achievement test.

\subsubsection{Normality Test for Achievement Scores}

This section dealt with the normality test for achievement scores of the pilot study. The score distribution was normal and possible to use the data for the t- test (Figure 1).

Pilot study of attitude questionnaire towards mechanic

Table 2. Pilot - test to determine the reliability of attitude questionnaire towards mechanics.

\begin{tabular}{ll}
\hline Cronbach's Alpha & Number of Items \\
\hline .80 & 33 \\
\hline
\end{tabular}

As indicated in table 2, the total items' Cronbach Alpha of pilot-test was .80 and hence, the attitude questionnaire towards mechanics was reliable. Since, the advisable value of Cronbach Alpha is greater than or equal to .65 .

Table 3. Pilot- tests to determine the reliability of attitude questionnaire towards mechanics and Shapio-Wilk normality test.

\begin{tabular}{|c|c|c|c|c|}
\hline Items & Mean & $\begin{array}{l}\text { Std. } \\
\text { Deviation }\end{array}$ & $\begin{array}{l}\text { Cronbach's } \\
\text { Alpha }\end{array}$ & $\begin{array}{l}\text { Shapio- } \\
\text { WilkSig. }\end{array}$ \\
\hline Q 1 & 3.6667 & 1.34519 & .799 & .004 \\
\hline Q 2 & 3.4667 & 1.30201 & .799 & .007 \\
\hline Q 3 & 3.4667 & 1.40746 & .811 & .036 \\
\hline Q 4 & 3.7333 & .96115 & .792 & .037 \\
\hline Q 5 & 3.2667 & 1.48645 & .796 & .044 \\
\hline Q 6 & 4.1333 & 1.18723 & .785 & .000 \\
\hline Q 7 & 3.6667 & 1.17514 & .796 & .000 \\
\hline Q 8 & 3.2000 & 1.56753 & .786 & .023 \\
\hline Q 9 & 4.3333 & 1.04654 & .804 & .000 \\
\hline Q 10 & 3.6000 & 1.45406 & .785 & .001 \\
\hline Q 11 & 4.0000 & 1.13389 & .803 & .001 \\
\hline Q 12 & 3.6000 & .91026 & .795 & .050 \\
\hline Q 13 & 3.4000 & .98561 & .776 & .004 \\
\hline Q 14 & 4.0667 & .88372 & .788 & .012 \\
\hline Q 15 & 3.7333 & .88372 & .792 & .005 \\
\hline Q 16 & 3.6667 & 1.11270 & .786 & .034 \\
\hline Q 17 & 3.4000 & 1.29835 & .789 & .006 \\
\hline Q 18 & 4.0667 & 1.22280 & .786 & .001 \\
\hline Q 19 & 3.5333 & 1.35576 & .789 & .011 \\
\hline Q 20 & 3.8000 & 1.26491 & .795 & .009 \\
\hline Q 21 & 4.2000 & .67612 & .791 & .004 \\
\hline Q 22 & 3.3333 & 1.23443 & .797 & .050 \\
\hline Q 23 & 4.3333 & 1.23443 & .787 & .000 \\
\hline Q 24 & 3.8667 & 1.06010 & .794 & .026 \\
\hline Q 25 & 4.0667 & 1.16292 & .792 & .001 \\
\hline Q 26 & 3.7333 & 1.03280 & .794 & .056 \\
\hline Q 27 & 3.6667 & 1.04654 & .788 & .052 \\
\hline Q 28 & 3.2667 & 1.22280 & .789 & .007 \\
\hline Q 29 & 3.4000 & 1.45406 & .786 & .026 \\
\hline Q 30 & 4.0000 & .92582 & .797 & .026 \\
\hline Q 31 & 3.1333 & 1.30201 & .799 & .012 \\
\hline Q 32 & 3.6667 & 1.11270 & .794 & .034 \\
\hline Q 33 & 4.0000 & 1.13389 & .791 & .001 \\
\hline \multicolumn{3}{|c|}{ Average Cronbach's Alpha } & \multicolumn{2}{|c|}{ Number of items } \\
\hline \multicolumn{3}{|c|}{.80} & \multicolumn{2}{|c|}{33} \\
\hline
\end{tabular}


The more consistent within-subject responses are, and the greater the reliability between subjects in the sample, the higher Cronbach's $\alpha$ will be. Therefore, as indicated in the above table the attitude questionnaire of each item was reliable. After calculation of Cronbach Alpha one question was removed since its Cronbach Alpha value was less than .65. Moreover, the distribution of each item was confirmed by Shapio-Wilk normality test and all of them were significant at .05 level of confidence. Histogram showed in the figure below was normality of attitude mean scores.

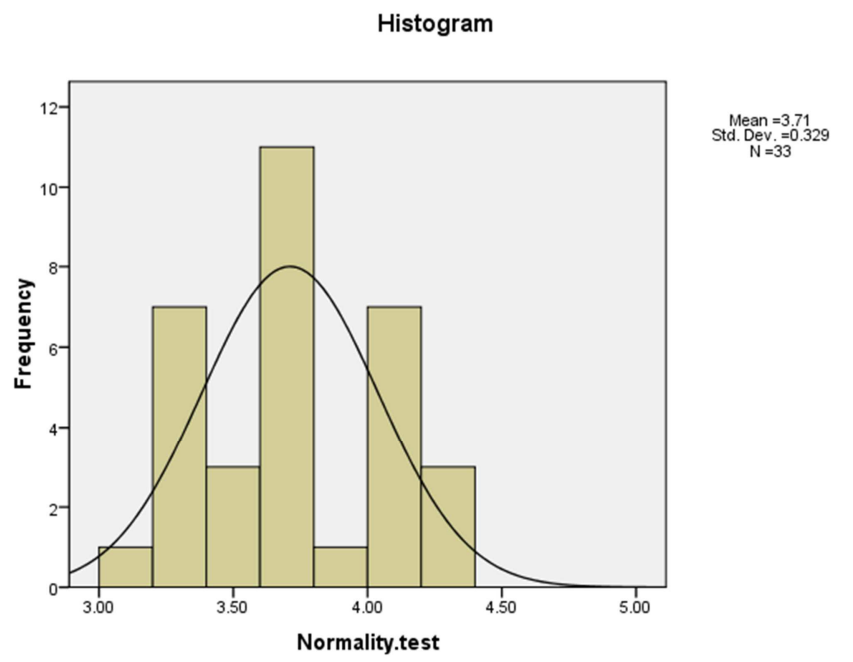

Figure 2. Histogram to check the normality of attitude questionnaire towards mechanics.

Figure 2. Indicates the shape of the histogram does fit with the ideal bell-shape. It is skewed the same to the right side and the left side. Therefore, the histogram does evident that the variable is normal that the mean distribution of the scores of the attitude towards mechanics questionnaire was normally distributed and hence, means, standard deviations and t-test could be used to determine students' attitude towards mechanics for both groups.

\subsection{Data Analysis}

After the data were collected, the means, standard deviations and t-values were calculated to determine the statistically significant difference observed between pre post achievement tests of both groups using SPSS version 16. Two tailed Paired samples t-test was used to compare the academic achievement of experimental group students before and after the treatment. Independent samples t-test was used to determine the significant difference observed between experimental and control group students' academic achievement before and after the treatment. Experimental group pre-test scores and post-test scores were compared to find out if any improvement in students' performance appeared after applying PBL. The post-test of both control and experimental groups were compared to find out if there was any significant difference in their achievement after the treatment at a level of 0.05 confidences.

To analyze students' interest towards mechanics; the normality of questionnaire items was confirmed by ShapioWilk normality test and normal curve histogram, then their means, standard deviation and t-values were calculated to determine the significant difference of students' attitude towards Mechanics by using SPSS version 16. Two tailed Paired samples t-test was used to compare the experimental group students' attitude towards mechanics before and after the treatment. Independent samples t-test was used to determine whether the significant difference observed between experimental and control group students' attitude towards mechanics after the treatment. Students' attitude towards PBL approach was analyzed by the frequency distribution of students' response. A bar chart was also used to show the distribution of experimental group student's attitude towards PBL.

\section{Results and Discussion}

The purpose of this study was to ascertain whether the use of problem-based learning in mechanic course had positive or negative impact up on achievement scores and attitude towards mechanics at college level.

Pre and Post Test Academic Achievement Results

To find out if the implementation of PBL has significant influence on students' academic achievement or not, data collected from the pre and posttests (AppendixC-1 and C-2) were analyzed.

Table 4. Results of pre and post test scores of both group students.

\begin{tabular}{llllll}
\hline \multicolumn{2}{l}{ Experimental Group } & \multicolumn{4}{l}{ Control Group } \\
\hline St.ID & Pre-test & Post-test & St.ID & Pre-test & Post-test \\
\hline E001 & 52 & 60 & C001 & 56 & 68 \\
E002 & 50 & 36 & C002 & 62 & 52 \\
E003 & 52 & 64 & C003 & 52 & 36 \\
E004 & 46 & 62 & C004 & 20 & 44 \\
E005 & 48 & 44 & C005 & 48 & 60 \\
E006 & 52 & 68 & C006 & 64 & 62 \\
E007 & 44 & 56 & C007 & 44 & 54 \\
E008 & 60 & 84 & C008 & 60 & 42 \\
E009 & 52 & 24 & C009 & 58 & 44 \\
E010 & 54 & 80 & C010 & 54 & 60 \\
E011 & 34 & 44 & C011 & 34 & 44 \\
E012 & 42 & 70 & C012 & 44 & 56 \\
E013 & 36 & 54 & C013 & 40 & 52 \\
E014 & 52 & 72 & C014 & 52 & 54 \\
E015 & 58 & 56 & C015 & 62 & 60 \\
E016 & 44 & 44 & C016 & 48 & 44 \\
E017 & 50 & 36 & C017 & 40 & 56 \\
E018 & 28 & 54 & C018 & 24 & 44 \\
E019 & 44 & 70 & C019 & 44 & 48 \\
E020 & 32 & 36 & C020 & 32 & 36 \\
E021 & 50 & 64 & C021 & 44 & 52 \\
E022 & 28 & 44 & C022 & 28 & 48 \\
E023 & 72 & 28 & C023 & 70 & 58 \\
E024 & 62 & 56 & C024 & 76 & 38 \\
E025 & 34 & 72 & C025 & 34 & 44 \\
E026 & 68 & 76 & C026 & 72 & 28 \\
E027 & 46 & 60 & C027 & 46 & 48 \\
E028 & 36 & 52 & C028 & 36 & 40 \\
E029 & 56 & 62 & C029 & 64 & 68 \\
E030 & 52 & 68 & C030 & 48 & 42 \\
Mean & 47.80 & 56.53 & Mean & 48.53 & 49.40 \\
\hline
\end{tabular}


As indicated in table 4 the academic achievement mean score of experimental group students were (47.80) and (56.53) before and after the treatment, respectively. Thus, shows experimental group students improved their academic achievement score after the implementation of problem-based learning. However, the academic achievement mean score of control group students were (48.53) and (49.40) before and after the treatment, respectively. As a result, control group students were also showed increased performance by the traditional method. This could be attributed to fresh memory of the topic and repeated exposure of the students for the same topic. But the effect was less pronounced as compared to experimental group. It is impossible to say the mean differences of students score were significant by calculating only the means as it indicated in (table 4). Therefore, the means observed in table 4 were also computed with t-test to see the significant difference between them. The purpose of using t-test was to compare the students' achievement mean scores before and after the treatment in order to decide whether a statistically significant difference exists between experimental group pre and post achievement scores and to decide whether there exists a statistically significant difference between experimental and control groups' post test scores.

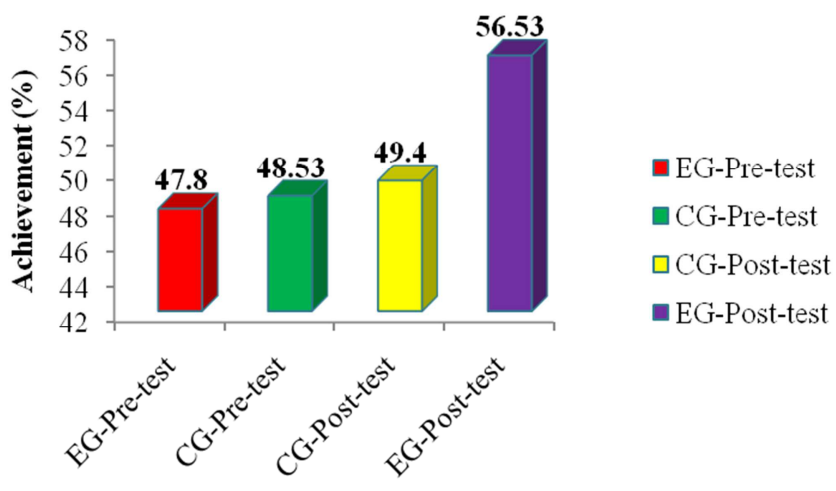

$\mathrm{EG}=$ experimental group, $\mathrm{CG}=$ control group.

Figure 3. Column chart shows the pre and post mean scores of experimental and control group.

The mean achievement scores of experimental and control groups was $47.80,48.53,56.53$, and 49.40 before and after the treatment respectively. As it was indicated in (Figure 3) the experimental group post-test mean achievement score was at the highest position. This showed that students' performance was greatly influenced by PBL approach compared to traditional approach. The column chart variation of the pre-test result of both groups almost seems the same.

Table 5. Two tailed paired samples t-test to determine the significant difference of academic achievement of experimental and control group students before and after the treatment.

\begin{tabular}{|c|c|c|c|c|c|c|c|c|}
\hline Groups & Tests & $\mathbf{N}$ & $\overline{\mathbf{X}}$ & Df & SD & $\mathbf{t}_{\mathrm{cal}}$ & Sig. (2-tailed) & $\mathbf{t}_{\mathrm{cri}}$ \\
\hline \multirow{3}{*}{ EG } & Pre-test & 30 & 47.80 & & & & & \\
\hline & Post-test & 30 & 56.53 & 29 & 17.30 & 2.766 & $.010^{*}$ & 2.045 \\
\hline & Mean gain & 8.73 & & & & & & \\
\hline \multirow[t]{2}{*}{ CG } & Post-test & 30 & 49.40 & 29 & 15.67 & .303 & .764 & 2.045 \\
\hline & Mean gain & 0.87 & & & & & & \\
\hline
\end{tabular}

*significant at the level of 0.05

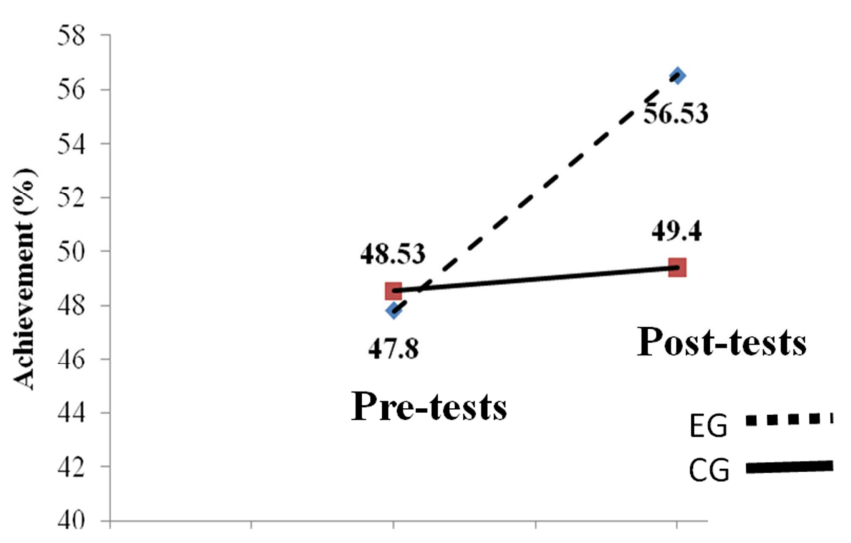

Figure 4. Line graph that shows the pre and post achievement test mean scores of students.

The decision about statistically significant difference between post and pre-test mean scores of experimental group students was made by comparing the calculated t-value with the critical $t$-value. In the above table 5 , calculated $t$-value $(\mathrm{t}$ $=2.766)$ which was greater than critical (table) $\mathrm{t}$-value $(\mathrm{t}=$ 2.045) for experimental group students. So, there is significant difference in academic achievement of experimental group students before and after the treatment. This shows that the academic achievement of the experimental group students was significantly improved after the treatment than their achievement before the treatment. However, calculated $\mathrm{t}$-value $(\mathrm{t}=.303)$ which was less than critical (table) $\mathrm{t}$-value $(\mathrm{t}=2.045)$ for control group students (table 5). This shows that control group students' improvement is not significant. These could be described more by the help of line graph as:

As shown in Figure 4 above experimental and control group students mean achievement scores varies from 47.80 to 56.53 , that is linearly increases and the slope of the graph is 8.73 whereas from 48.53 to 49.40 , almost horizontal and the slope of the graph is 0.87 before and after the treatment respectively. Thus, showed that there was a great improvement of experimental group students' achievement means scores after the treatment than the control group students. As a result, problem-based learning improves students' achievement in mechanics.

Effect size calculation of achievement test

Effect size is simply a way of quantifying the size of the difference between two groups. 


$$
\begin{aligned}
& \text { Effect size }=\frac{\{\text { mean of expgroup }\}-\{\text { mean of cont group }}{\text { standard devation }} \\
& S D_{\text {pooled }}=\frac{\sqrt{\left(N_{E}-1\right) S D_{E}^{2}+\left(N_{C}-1\right) S D_{C}^{2}}}{N_{E}+N_{C}-2}(\text { pooled })
\end{aligned}
$$

(Where $\mathrm{N}_{\mathrm{E}}$ and $\mathrm{N}_{\mathrm{C}}$ are the numbers in the experimental and control groups, respectively, and $\mathrm{SD}_{\mathrm{E}}$ and $\mathrm{SD}_{\mathrm{C}}$ are their standard deviations.)

$$
\begin{gathered}
\mathrm{SD}_{\text {pooled }}=\sqrt{\frac{(30-1) *(12.565)^{2}+(30-1) *(14.22)^{2}}{30+30-2}}=\sqrt{\frac{(29 * 157.879)+(29 * 202.208)}{58}}=\sqrt{\frac{10442.52}{58}}=\sqrt{180}=13.42 \\
\text { Effect size }\left(\eta^{2}\right)=\frac{\text { EGmean }- \text { CGmean }}{S D_{\text {pooled }}}=\frac{47.80-48.53}{13.42}=-0.054
\end{gathered}
$$

Effect size $\left(\eta^{2}\right) \cong 0.0$, effect size before the treatment

According to Cohen (1969) an effect size of 0.5 is described as medium and is large enough to be visible, below 0.5 is small and above 0.5 is large, the small effect size indicated that two groups have no significant difference. Therefore, the effect size before treatment is 0.0 . This show the two groups were equivalent before the treatment $(50 \%)$ control group (50\%) experimental.

In the same procedure the effect size after the treatment becames:

$$
\begin{aligned}
& S D_{\text {pooled }}= \frac{\sqrt{\left(N_{E}-1\right) S D_{E}{ }^{2}+\left(N_{C}-1\right) S D_{C}{ }^{2}}}{N_{E}+N_{C}-2}(\text { pooled })=\sqrt{\frac{(30-1) *(15.25)^{2}+(30-1) *(9.72)^{2}}{30+30-2}} \\
&= \sqrt{\frac{(29 * 232.56)+(29 * 94.48)}{58}}=\sqrt{163.52}=12.79 \\
& \text { Effect size } \eta^{2}=\frac{\text { EGmean }- \text { CGmean }}{S D_{\text {pooled }}}=\frac{56.53-49.40}{12.79}=0.56
\end{aligned}
$$

$\eta^{2}=0.6$, effect size after the treatment

An effect-size of 0.6 indicates that the average person in the experimental group would score higher than $73 \%$ of a control group that was initially equivalent.

Table 6. Independent samples t-test to determine academic achievement of students before and after the treatment.

\begin{tabular}{lllllllll}
\hline Tests & Groups & $\mathbf{N}$ & $\overline{\mathbf{X}}$ & $\mathbf{D f}$ & $\mathbf{S D}$ & $\mathbf{t}_{\text {cal }}$ & Sig. (2-tailed) & $\mathbf{t}_{\text {cri }}$ \\
\hline \multirow{3}{*}{ Before } & EG & 30 & 47.80 & & 10.91 & & & \\
& CG & 30 & 48.53 & 58 & 14.22 & -.224 & .823 & 1.671 \\
& Mean gain & 0.73 & & & & & & \\
\multirow{3}{*}{ After } & EG & 30 & 56.53 & & 15.29 & 2.156 & $.035^{*}$ & 1.671 \\
& CG & 30 & 49.40 & 58 & 9.72 & & & \\
\hline
\end{tabular}

*significant at the level of 0.05

There was no significant difference observed between the academic achievements of students in both groups before the treatments with 58 degree of freedom at 0.05 level of confidence (table 6). Since the calculated $t$-value $(t=-.224)$ was less than the critical $t$-value $(t=1.671)$. This shows that both groups had equivalent prior knowledge about mechanics and hence, tantamount to say equivalent groups. As it was indicated in table 6, significant difference was observed between experimental and control group academic achievement mean scores after the treatment with 58 degree of freedom at 0.05 level of confidence. Since the calculated t- value (2.156) exceeded the table value (1.671). This indicates that the academic performance of the experimental group was improved than the control group.

The Pre and Post Attitude towards Mechanics:

After reversing students 'negative scores into positive scores, students' interest towards mechanics were assessed and noted down by using the Quintet Likert scale. The tables below represent results of students' response of attitude questionnaire towards mechanics. 
Table 7. Students' attitude scores towards mechanics before and after the treatment.

\begin{tabular}{|c|c|c|c|c|c|}
\hline \multicolumn{3}{|c|}{ Experimental Group } & \multicolumn{3}{|c|}{ Control Group } \\
\hline St.ID & $\begin{array}{l}\text { Pre- } \\
\text { Attitude }\end{array}$ & $\begin{array}{l}\text { Post- } \\
\text { Attitude }\end{array}$ & St. ID & $\begin{array}{l}\text { Pre- } \\
\text { Attitude }\end{array}$ & $\begin{array}{l}\text { Post- } \\
\text { Attitude }\end{array}$ \\
\hline E001 & 125 & 136 & $\mathrm{C} 001$ & 127 & 126 \\
\hline E002 & 125 & 130 & $\mathrm{C} 002$ & 123 & 119 \\
\hline E003 & 125 & 136 & $\mathrm{C} 003$ & 127 & 124 \\
\hline E004 & 116 & 131 & C004 & 124 & 124 \\
\hline E005 & 125 & 128 & $\mathrm{C} 005$ & 127 & 125 \\
\hline E006 & 117 & 129 & $\mathrm{C} 006$ & 129 & 128 \\
\hline E007 & 121 & 136 & $\mathrm{C} 007$ & 129 & 128 \\
\hline E008 & 121 & 130 & $\mathrm{C} 008$ & 128 & 126 \\
\hline E009 & 126 & 136 & C009 & 127 & 126 \\
\hline E010 & 123 & 131 & $\mathrm{C} 010$ & 123 & 121 \\
\hline E011 & 125 & 128 & $\mathrm{C} 011$ & 122 & 122 \\
\hline E012 & 127 & 129 & $\mathrm{C} 012$ & 123 & 124 \\
\hline E013 & 128 & 131 & $\mathrm{C} 013$ & 121 & 121 \\
\hline E014 & 128 & 135 & C014 & 125 & 121 \\
\hline E015 & 128 & 128 & $\mathrm{C} 015$ & 125 & 125 \\
\hline E016 & 130 & 131 & $\mathrm{C} 016$ & 130 & 129 \\
\hline E017 & 124 & 130 & $\mathrm{C} 017$ & 123 & 124 \\
\hline E018 & 125 & 131 & $\mathrm{C} 018$ & 120 & 120 \\
\hline E019 & 127 & 127 & C019 & 127 & 127 \\
\hline E020 & 131 & 135 & $\mathrm{C} 020$ & 131 & 130 \\
\hline E021 & 124 & 131 & $\mathrm{C} 021$ & 119 & 120 \\
\hline E022 & 124 & 127 & C022 & 126 & 125 \\
\hline E023 & 125 & 125 & $\mathrm{C} 023$ & 125 & 123 \\
\hline E024 & 120 & 133 & C024 & 127 & 127 \\
\hline E025 & 129 & 132 & $\mathrm{C} 025$ & 124 & 125 \\
\hline E026 & 128 & 128 & $\mathrm{C} 026$ & 125 & 124 \\
\hline E027 & 127 & 129 & C027 & 128 & 126 \\
\hline E028 & 129 & 131 & C028 & 129 & 129 \\
\hline E029 & 123 & 134 & C029 & 126 & 124 \\
\hline E030 & 129 & 133 & $\mathrm{C} 030$ & 132 & 130 \\
\hline Mean & 125.17 & 131.03 & Mean & 125.73 & 124.77 \\
\hline
\end{tabular}

As indicated in the above table 7 , the mean attitude score of experimental group students were (125.17), (131.03) before and after the treatment, respectively. Thus, showed there was difference in mean scores of experimental group students' interest towards mechanics before and after the treatment. However, it is impossible to say the mean differences of students score were significant by calculating only the means as it indicated in the above table. Therefore, the means observed in the above table were also computed with $\mathrm{t}$-test to see if there were the significant differences between them. In order to decide whether a statistically significant difference exists between experimental group pre and post-attitude towards mechanics the calculated and critical t-value was compared in the table 8 below.

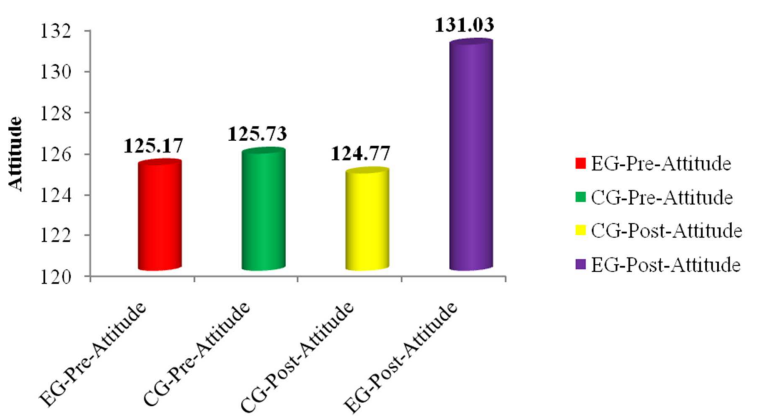

Figure 5. Column chart that shows the mean value of students' interest before and after treatment.

Figure 5. Indicates 125.17, 125.73, 131.03, 124.77 and are attitude towards mechanics mean scores of experimental and control group students, respectively. Thus, showed that experimental group attitude towards mechanics was highly increased after the implementation of PBL, but the converse was true for control group students.

Table 8. Two tailed paired samples t-test to determine the significant difference before and after the treatment of the experimental group.

\begin{tabular}{|c|c|c|c|c|c|c|c|c|}
\hline Groups & Attitude & $\mathbf{N}$ & $\overline{\mathbf{X}}$ & df & SD & $\mathbf{t}_{\mathrm{cal}}$ & Sig. (2-tailed) & $\mathbf{t}_{\text {cri }}$ \\
\hline \multirow{3}{*}{ EG } & Pre- attitude & 30 & 125.17 & & & & & \\
\hline & Post- attitude & 30 & 131.03 & 29 & 4.64 & 6.930 & $.000 *$ & 2.045 \\
\hline & Mean gain & 5.87 & & & & & & \\
\hline \multirow{3}{*}{$\mathrm{CG}$} & Pre- attitude & 30 & 125.73 & & & & & \\
\hline & Post- attitude & 30 & 124.77 & 29 & 1.35 & 3.918 & $.000 *$ & 2.045 \\
\hline & Mean gain & 0.97 & & & & & & \\
\hline
\end{tabular}

*significant at the level of 0.05

As indicated in table 8, there was significant difference of experimental group students' attitude towards mechanics after the treatment with 29 degree of freedom at 0.05 level of confidence, as the calculated (6.930) $\mathrm{t}$-value exceeded the critical t-value (2.045). So, it could be said that experimental group students' attitude towards mechanics was increased after the treatment. However, control group students' attitude towards mechanics decreases after traditional instruction. This decrement might result from repetition of the same procedure throughout the instruction for all topics or it might the result of passive participation of students during traditional instruction. These increment and decrement could be shown more by the help of line chart as follow:

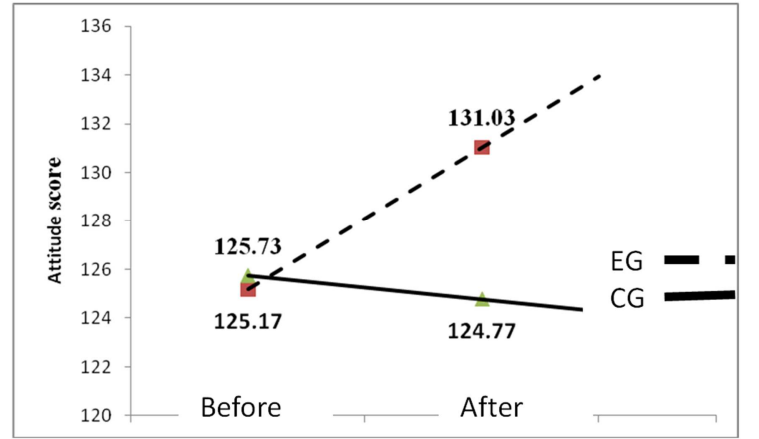

Figure 6. Line graph that shows the variation between students' perception before and after treatment of both groups. 
As shown in Figure 6 above experimental group students mean attitude scores varies from 125.17 to 131.03 , whereas from 125.73 to 124.77 for control group students before and after the treatment, respectively. Thus, showed there was a great improvement of experimental group students' attitude towards mechanics after the treatment.
However, the slope of line was negative for control group students. This indicates that their attitude towards mechanics decreased. As a result, problem-based learning improves students' attitude towards mechanics but, not traditional method.

Table 9. Independent samples t-test to determine the significant difference between experimental and control groups' attitude towards mechanics.

\begin{tabular}{|c|c|c|c|c|c|c|c|c|}
\hline Attitude & Groups & $\mathbf{N}$ & $\overline{\mathbf{X}}$ & df & SD & $\mathbf{t}_{\mathrm{cal}}$ & Sig. (2-tailed) & $t_{\text {cri }}$ \\
\hline \multirow{3}{*}{ Before } & EG & 30 & 125.17 & & 3.57 & \multirow{3}{*}{-.651} & \multirow{3}{*}{.518} & \multirow{3}{*}{1.671} \\
\hline & $\mathrm{CG}$ & 30 & 125.73 & 58 & \multirow{2}{*}{3.16} & & & \\
\hline & Mean gain & 0.56 & & & & & & \\
\hline \multirow{3}{*}{ After } & EG & 30 & 131.03 & & \multirow{2}{*}{3.05} & \multirow{3}{*}{8.011} & \multirow{3}{*}{$.000^{*}$} & \multirow{3}{*}{1.671} \\
\hline & $\mathrm{CG}$ & 30 & 124.77 & 58 & & & & \\
\hline & Mean gain & 6.26 & & & 3.01 & & & \\
\hline
\end{tabular}

*significant at the level of 0.05

As it was indicated in the above table, the calculated $\mathrm{t}$ value (8.011) exceeded the critical t-value (1.671) with 58 degree of freedom at 0.05 level of confidence after the treatment. This indicates that after the treatment there was significant difference in experimental and control group students' attitude towards mechanics. However, the $t_{\text {cal }}(.651)$ was less than $t_{\text {cri }}(1.671)$. This shows that the no significant difference between the two groups before the treatments. It is evident that experimental group students' attitude towards mechanics was improved after the treatment.

Effect size calculation of attitude towards mechanics

Effect size is simply a way of quantifying the size of the difference between two groups.

$$
\begin{gathered}
\text { Effect size }=\frac{\{\text { mean of expgroup }\}-\{\text { mean of cont group }}{\text { standard devation }} \\
S D_{\text {pooled }}=\frac{\sqrt{\left(N_{E}-1\right) S D_{E}{ }^{2}+\left(N_{C}-1\right) S D_{C}{ }^{2}}}{N_{E}+N_{C}-2}(\text { pooled })
\end{gathered}
$$

(Where $\mathrm{N}_{\mathrm{E}}$ and $\mathrm{N}_{\mathrm{C}}$ are the numbers in the experimental and control groups, respectively, and $\mathrm{SD}_{\mathrm{E}}$ and $\mathrm{SD}_{\mathrm{C}}$ are their standard deviations.)

$$
\mathrm{SD}_{\text {pooled }}=\sqrt{\frac{(30-1)^{*}(3.57)^{2}+(30-1) *(3.16)^{2}}{30+30-2}}=\sqrt{\frac{(29 * 12.74)+(29 * 9.99)}{58}}=\sqrt{\frac{659.17}{58}}=\sqrt{11.37}=3.37
$$

Effect size $\left(\eta^{2}\right)=\frac{\text { EGmean }- \text { CGmean }}{S D_{\text {pooled }}}=\frac{125.17-125.73}{3.37}=-0.17$

Effect size $\left(\eta^{2}\right) \cong-0.17$, effect size before the treatment

According to Cohen (1969) an effect size of 0.5 is described as medium and is large enough to be visible, below 0.5 is small and above 0.5 is large, the small effect size indicated that two groups have no significant difference.

In the same procedure the effect size after the treatment becames:

$$
\begin{aligned}
S D_{\text {pooled }}= & \frac{\sqrt{\left(N_{E}-1\right) S D_{E}^{2}+\left(N_{C}-1\right) S D_{C}^{2}}}{N_{E}+N_{C}-2}(\text { pooled })=\sqrt{\frac{(30-1) *(3.05)^{2}+(30-1) *(3.01)^{2}}{30+30-2}} \\
= & \sqrt{\frac{(29 * 9.30)+(29 * 9.06)}{58}}=\sqrt{9.18}=3.03 \\
& \text { Effect size }\left(\eta^{2}\right)=\frac{E G m e a n-C \text { Gmean }}{S D_{\text {pooled }}}=\frac{131.03-124.77}{3.03}=2.06
\end{aligned}
$$

$\eta^{2}=2.06$, effect size after the treatment

An effect-size of 2.06 indicates that the effect size was very large after the treatment. 
Table 10. Frequency distribution of experimental group students' to know their attitude towards mechanics after the implementation of PBL.

\begin{tabular}{|c|c|c|c|c|c|c|c|c|c|c|}
\hline \multirow{2}{*}{ No of items } & \multicolumn{2}{|c|}{ Strongly agree } & \multicolumn{2}{|c|}{ Agree } & \multicolumn{2}{|c|}{ Neutral } & \multicolumn{2}{|c|}{ Disagree } & \multicolumn{2}{|c|}{ Strongly disagree } \\
\hline & $\mathbf{N}$ & $\%$ & $\mathbf{N}$ & $\%$ & $\mathbf{N}$ & $\%$ & $\mathbf{N}$ & $\%$ & $\mathbf{N}$ & $\%$ \\
\hline 1 & 16 & 53.30 & 9 & 30.00 & 0 & 0.00 & 3 & 10.00 & 2 & 6.70 \\
\hline 2 & 18 & 60.00 & 9 & 30.00 & 0 & 0.00 & 3 & 10.00 & 0 & 0.00 \\
\hline 3 & 16 & 53.30 & 12 & 40.00 & 2 & 6.70 & 0 & 0.00 & 0 & 0.00 \\
\hline 4 & 14 & 46.70 & 12 & 40.00 & 3 & 10.00 & 1 & 3.30 & 0 & 0.00 \\
\hline 5 & 9 & 30.00 & 14 & 46.70 & 4 & 13.30 & 3 & 10.00 & 0 & 0.00 \\
\hline 6 & 10 & 33.30 & 9 & 30.00 & 7 & 23.00 & 3 & 10.00 & 1 & 3.30 \\
\hline 7 & 17 & 56.70 & 9 & 30.00 & 3 & 10.00 & 1 & 3.30 & 0 & 0.00 \\
\hline 8 & 10 & 33.30 & 6 & 20.00 & 4 & 13.30 & 6 & 20.00 & 4 & 13.30 \\
\hline 9 & 6 & 20.00 & 14 & 46.70 & 2 & 6.70 & 4 & 13.30 & 4 & 13.30 \\
\hline 10 & 14 & 46.70 & 10 & 33.30 & 2 & 6.70 & 4 & 13.30 & 0 & 0.00 \\
\hline 11 & 11 & 36.70 & 10 & 33.30 & 5 & 16.70 & 3 & 10.00 & 1 & 3.30 \\
\hline 12 & 15 & 50.00 & 10 & 33.30 & 0 & 0.00 & 3 & 10.00 & 2 & 6.70 \\
\hline
\end{tabular}

As indicated in table 10, on average from 30 students, more than 24 students showed positive attitude towards PBL. In detail $83.3 \%$ of students found that PBL helped them to better understand; $90 \%$ found that PBL lesson was meaningful and $93.3 \%$ found it was well organized. On the other hand, $36.7 \%$ and $46.7 \%$ of students did not agree with the idea that PBL encouraged interaction with other students and they effectively used the material provided in this topic, respectively. This showed that there is individual difference among students when students exposed to new learning approach because there are three types of students in the class: fast learners, medium learners, and slow learners. Moreover, $80.0 \%$ found that PBL took more time than conventional based approach. Generally, $83.3 \%$ of students would like to use PBL again. This indicated that experimental group students showed positive attitude towards PBL. The above table 10 could be described in detail using column graph as follow:

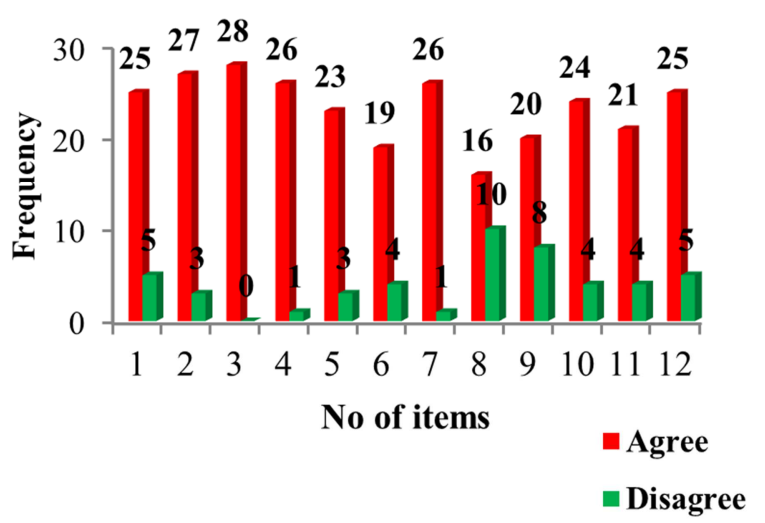

Figure 7. Column chart that shows frequency distribution of students' attitude towards $P B L$.

As indicated in Figure 7 above most students in each item showed positive attitude towards PBL. However, 10 and 8 students disagreed on the idea that PBL encouraged interaction with other students and they effectively used the material provided in this topic, respectively. Thus, showed those students might not understand the concept of these questions.

\section{Conclusion}

Overall, this research showed that PBL had shown a positive impact in achievement, and attitude towards mechanics. This has proven that PBL had more effective compared to traditional approach. PBL had helped in improving the achievement and attitude of students. It exposes students more to realities of life and tend to work as scientist and acquire knowledge by themselves which the teacher only corrects their misconceptions. Problem-based learning removes teacher as a dictator and sole owner of knowledge which render students passive.

Students are actively involved in problem-based learning technique which is not so in conventional learning method. PBL improves the academic achievement of physics students.

PBL approach is more effective in improving students' academic achievement and attitude towards mechanics. Thus, implies that PBL enhances students' academic performance and their perception about mechanics learning and also they have positive attitude towards PBL.

\section{Recommendation}

Based on this research, the researcher recommended the following points:

1. Physics teachers should adopt the use of PBL technique at college level.

2. Consciousness about this approach should be developed in college students.

3. Educators are urged to consider the PBL approach as one of their teaching strategies.

4. Problem based learning requires material usage in a large extent. For this reason, science classes should be supplied with the necessary materials and equipment.

5. Problem based learning requires in class and out of class activities.

6. Creating a school atmosphere which is suitable with PBL approach is important for practicing the method. Support from the other disciplines' teachers, school administrators, and science teachers to the PBL 
practices is important since it is an interdisciplinary approach. Consciousness about this approach should be developed in school personnel.

\section{Acknowledgements}

I would like to thank everyone who helped me to complete this study successfully. I would like to thank my advisors Dr. Girma Goro and Miss. Emilie Pamplona for their guidance throughout my work.

I would also like to take the opportunity to thank all my friends who helped me to complete the study at GBCTE.

Finally, I would like to thank my family who gave me the support I needed to complete my study.

\section{References}

[1] Ruhan, O. T., 2007. The Effect of Problem- Based active Learning in Science Education on Students' Academic Achievement, Attitude and Concept Learning. Eurasia Journal of Mathematics, Science and Technology Education, 3 (1): 7181

[2] Okereke, S. C., 2006. Effect of prior knowledge of implementing of mathematical tasks/concepts to career types and gender on students' achievement, interest and retention. In U. Nzewi (Ed) STAN Proceedings of the 47th Annual Conference: 253-259.

[3] Chin, C., and L. Chia, 2004. Implementing project work in biology through problem-based learning. Journal of Biological Education, 38 (2): 69-75.

[4] Walker, J. T., and S. P. Lofton, 2003. Effect of Problem Based Learning Curriculum on Students' Perceptions of Self-directed Learning. Issues in Educational Research, 13, University of Mississipi Medical Centre.

[5] Dewey, J., 1938. Experience and education A Touchstone Book, Kappa Delta Pi, New York. 5.
[6] Rhem, J., 1999. Problem Based Learning: An Introduction. The national Teaching and Learning Forum, 8, 1, Orxy Press USA.

[7] Herreid, C. F., 2003. The Death of Problem Based Learning. Journal of College Science Teaching, 32, 6.

[8] Gallagher, S. A., 1997. Problem-Based Learning: Where did it come from, what does it do, and where is it going? Journal for the education of the Gifted, 20 (4): 332-362.

[9] Lambros, A., 2002. Problem Based Learning in K-8 Classroom: A Teacher Guide to Implementation. California. Corvin Press Inc.

[10] Yager, R. E., 2000. A vision for what science education should be like for the first 25 years of a new millennium. School Science and Mathematics, 100: 327-341.

[11] Iroegbu, T. O., 2004. Enwisdomization and African philosophy.

[12] Akinlaye, F. A., 1998. Teacher-guided inquiry, guideddiscussion and students' learning outcomes in some aspects of social studies. Unpublished PhD Thesis University of Ibadan, Ibadan.

[13] Craker, D. E., 2006. Attitudes toward science of students enrolled in introductory level science courses at UW-La Crosse, UW-L Journal of Undergraduate Research IX, 1.

[14] Udousoro, U. J., 2002. The relative effects of computer and text-assisted programmed instruction on students' learning outcomes in physics. Unpublished Ph.D Thesis, University of Ibadan.

[15] Gallagher, S., W. Stepien, B. Sher, and D. Workman, 1999. Implementing problem-based learning in science classrooms. School Science and Mathematics, 95: 136146.

[16] Ali, R., 2010. Effect of Using Problem Solving Method in Teaching Mathematics. Asian.

[17] Chin, C., and L. G. Chia, 2004. Problem-based learning: Using students' questions to drive knowledge construction. Science Education, 88 (5): 707-727. 